\title{
Plant volatile emission depends on the species composition of the neighboring plant community
}

\author{
Rose N. Kigathi ${ }^{1,2,4}$, Wolfgang W. Weisser ${ }^{1,3}$, Michael Reichelt ${ }^{2}$, Jonathan Gershenzon ${ }^{2}$ and Sybille B. Unsicker ${ }^{2^{*}}$ (D)
}

\begin{abstract}
Background: Plants grow in multi-species communities rather than monocultures. Yet most studies on the emission of volatile organic compounds (VOCs) from plants in response to insect herbivore feeding focus on one plant species. Whether the presence and identity of neighboring plants or plant community attributes, such as plant species richness and plant species composition, affect the herbivore-induced VOC emission of a focal plant is poorly understood.
\end{abstract}

Methods: We established experimental plant communities in pots in the greenhouse where the focal plant species, red clover (Trifolium pratense), was grown in monoculture, in a two species mixture together with Geranium pratense or Dactylis glomerata, or in a mixture of all three species. We measured VOC emission of the focal plant and the entire plant community, with and without herbivory of Spodoptera littoralis caterpillars caged on one red clover individual within the communities.

Results: Herbivory increased VOC emission from red clover, and increasing plant species richness changed emissions of red clover and also from the entire plant community. Neighbor identity strongly affected red clover emission, with highest emission rates for plants growing together with D. glomerata.

Conclusion: The results from this study indicate that the blend of VOCs perceived by host searching insects can be affected by plant-plant interactions.

Keywords: Biodiversity effects, Experimental grassland, Fabaceae, Geraniaceae, Herbivore-induced plant volatiles (HIPV), Poaceae

\section{Background}

Plants constitutively emit volatile organic compounds (VOCs) from flowers, leaves, and roots. Emission generally increases when plants are attacked by antagonists such as insect herbivores or pathogens $[26,58]$. The function of these VOCs is diverse and not fully understood. VOCs play a role in protection against abiotic stresses such as ozone, light and temperature (recently reviewed by [40]), act as attractant in biotic interactions such as pollination $[6,10,28]$, or seed dispersal [50], or serve as direct or indirect defense against natural enemies $[5,6,44]$ including defense priming $[15,16,18]$.

\footnotetext{
* Correspondence: sunsicker@ice.mpg.de

${ }^{2}$ Department of Biochemistry, Max Planck Institute for Chemical Ecology,

Hans-Knöll Str. 8, 07745 Jena, Germany

Full list of author information is available at the end of the article
}

There are also further functions of VOCs in intra- and interspecific plant communication [29, 30,36].

So far, single plant individuals have been the main focus of studies investigating the role of plant VOCs in biotic interactions. Because plants most often interact with conspecific and heterospecific plants in the field, several recent reviews have suggested that studies should be expanded to more natural situations in order to understand the evolutionary roles of herbivore induced plant volatiles (HIPVs) under natural conditions [22, 47]. In particular, it seems essential to challenge plants by growing them with conspecific and/or heterospecific neighbors of different plant community complexities, such as with increasing plant diversity [31].

Recent studies have demonstrated that neighbor identity can drastically affect the defense chemistry of a focal 
plant species. In a study by Broz et al. [3], Centaurea maculosa plants growing next to conspecific neighbors contained higher levels of phenolic compounds after elicitation with methyl jasmonate than plants growing with a heterospecific grass species. Neighbor identity also significantly affected the VOC emission from the legume red clover (Trifolium pratense) [35]. In competition with conspecific neighbors, red clover plants emitted lower amounts of constitutive and herbivore induced VOCs as compared to those growing in inter-specific competition with the orchard grass Dactylis glomerata [35]. Neighbor-induced changes in plant allocation to defense compounds likely affect the resistance against biotic stresses and can thus ultimately affect the persistence of plants in a community.

Increasing plant species richness in a plant community has been shown to result in increased insect herbivory [39], increased visits of pollinators [12] and changes in more complex plant-insect interactions $[13,57]$. These ecosystem-level effects of plant diversity are often the consequence of plastic responses of plants to the community in which they grow [56] and may thus also affect plant defence. While there are studies on how plant diversity affects nutrient allocation to growth and reproduction across different plant diversity levels (e.g. [21]), the effects of plant species richness on the investment of plants into defense have rarely been investigated. Mraja et al. [43] showed that iridoid glycoside defenses in ribwort plantain (Plantago lanceolata) were significantly affected by plant species richness in experimental grasslands. For VOC emissions, effects of plant diversity have been postulated [49], but empirical evidence is scarce (recently reviewed by [42]).

The odor released from plant communities is composed of VOCs emitted from individual plants within these communities. Host searching insect herbivores or parasitoids and predators foraging in complex plant communities are thus always confronted with a diverse mixture of plant derived VOCs. As insects have been shown to perceive even minute amounts of such VOCs [6], it seems likely that quantitative and/or qualitative changes in the VOC emission of plant communities can negatively or positively affect the host- or prey searching behavior of insects. Conversely, if a target plant under attack by an insect herbivore 'cries for help' with an amplified release of herbivore-induced VOCs, it's attractiveness to a host seeking parasitoid or an insect predator may be diminished due to neighbor-inflicted masking of the plants' VOC signals. These complexities of plant community $\mathrm{VOC}$ emissions and the resulting responses of searching insects are only starting to be addressed. An understanding of the role of VOCs in plant-insect interactions in the field thus requires analyzing VOC emission not only at the level of a focal plant, but also at the level of the plant community.

In this study we investigated the effects of plant species composition and plant species richness on constitutive and herbivore-induced VOC emission of the focal plant species, red clover (Trifolium pratense), and from the entire plant community including red clover. In an experimental greenhouse study we created grassland communities with a plant species richness gradient ranging from one to three species, by combining red clover with the forb Geranium pratense and the grass Dactylis glomerata. To analyze the effect of herbivory on VOC emission, we compared red clover fed upon by larvae of the generalist lepidopteran Spodoptera littoralis versus untreated control plants. Although this species is not recorded as an herbivore on red clover so far, we chose it, as it is a broad generalist that reliably consumes significant quantities of leaf material. Previous studies have successfully employed $S$. littoralis for unravelling plant responses to herbivory $[33,37]$ including our own studies $[17,34]$.

We addressed the following specific questions:

(1) Is the VOC emission of red clover and of the entire plant community influenced by the composition and diversity of the surrounding plant community?

(2) Are there effects of plant identity, i.e. does it matter for VOC emission if red clover grows together with D. glomerata or G. pratense?

(3) Are VOC emissions from a single herbivore induced plant detectable at the community level?

\section{Results}

\section{Trifolium pratense biomass and herbivory}

The biomass of the focal T. pratense plants was affected by plant species richness, species composition and the identity of the neighbouring plants (Additional file 1: Figure S1A and Table S1). T. pratense plants growing with $D$. glomerata (TD and TDG mixtures) had lower biomass compared to plants in mixtures without the species, while plants growing with G. pratense were not different from those growing in $T$. pratense monoculture (Additional file 1: Table S1, Model 3). Additional file 1: Figure S1 illustrates that $T$. pratense individuals growing in plant species mixtures had a lower biomass than individuals growing in monocultures. The model with the lowest AIC (best fit) for T. pratense biomass was the one with species composition (Model 2, Additional file 1: Table S1A).

For entire plant communities, species richness, species composition and the identity of the neighbouring plants affected total biomass (Additional file 1: Figure S1B and Table S1B). Biomass was highest in the most diverse community and communities with $D$. glomerata were 
found to have higher biomass than other communities. The model with the lowest AIC for community biomass was the one with neighbor identity (Model 3, Additional file 1: Table S1B).

The percent leaf area loss due to Spodoptera littoralis caterpillar feeding was on average $18.4 \pm 2.0 \%$ (calculated across treatments). Herbivory tended to increase with species richness, but this was not significant (Additional file 1: Figure S2 and Table S2 Model 1). Plant species composition and neighbor identity (presence of D. glomerata or G. pratense) did not affect caterpillar herbivory (Additional file 1: Table S2, Models 2 and 3).

\section{VOC emission from Trifolium pratense}

T. pratense emitted very low amounts of VOCs when there was no herbivory. Upon caterpillar damage, total VOC emission from $T$. pratense was found to be three-fold higher than the emission of control plants (emissions: Table 1, statistical results on the effect of herbivory: Additional file 1: Table S3). S. littoralis feeding resulted in an increased emission of five compounds, 1-octen-3-ol, the monoterpenes $(E)$ - $\beta$-ocimene and (Z)- $\beta$-ocimene), the sesquiterpene $(E)$ - $\beta$-caryophyllene and 4,8-dimethyl-1,3,7-nonatriene (DMNT) (Tables 1 and 2, statistical results of the herbivory effect: Additional file 1: Table S3).

Plant species richness did not affect VOC emission from the focal plant species $T$. pratense, (Fig. 1a-e, Tables 1 and 2A, Model 1, for full results see Additional file 2: Table S4A). Species composition had no effect on the emission of major groups of VOCs, when considered separately, but significantly affected the total amount of VOC emission (Fig. 1a-e, Tables 1 and 2A, Model 2, Additional file 2: Table S4). Neighbor identity did significantly affect VOC emission of various groups and Model 3 had the lowest AIC for all major groups of VOCs (Table 2 Additional file 2: Table S4A). The strong effect of the identity of the neighboring plants on $T$. pratense VOC emission was mainly due to the presence of $D$. glomerata. T. pratense plants growing in communities containing the grass species D. glomerata emitted higher amounts of monoterpenes and green leaf volatiles, and as a consequence of this, the overall VOC emissions from $T$. pratense in these communities was higher (Fig. 1a, d, Tables 1 and 2A, Model 3, Additional file 2: Table S4A). T. pratense growing together with $G$. pratense showed a significantly lower emission of the homoterpene DMNT (Fig. 2c, Tables 1 and 2A, Model 3, Additional file 2: Table S4A).

Table 1 Constitutive and herbivore-induced VOCs released from single individuals of the focal plant species Trifolium pratense growing in pot communities of differing species compositions. T. pratense plants were either grown in monoculture (1 sp), in two species mixtures with Geranium pratense (TG) or Dactylis glomerata (TD), or in three species mixtures with D. glomerata and G. pratense (3 spp). T. pratense individuals in half of the experimental pot communities were infested with Spodoptera littoralis caterpillars (herbivory treatment). Values represent mean VOC emissions (ng g $\mathrm{g}^{-1} \mathrm{~h}^{-1}$ ) \pm SEM from single T. pratense individuals

\begin{tabular}{|c|c|c|c|c|c|c|c|c|c|c|}
\hline \multirow[t]{2}{*}{ Compounds } & \multicolumn{5}{|l|}{ Control } & \multicolumn{5}{|l|}{ Herbivory } \\
\hline & $1 \mathrm{sp}$. & 2 spp. & 3 spp. & $\mathrm{TG}$ & TD & $1 \mathrm{sp}$. & 2 spp. & 3 spp. & $\mathrm{TG}$ & TD \\
\hline \multicolumn{11}{|l|}{ Monoterpenes ${ }^{* d}$} \\
\hline$(E)-\beta$-ocimene* & $0.5 \pm 0.5$ & $0.9 \pm 0.6$ & $1.7 \pm 1.0$ & - & $1.6 \pm 1.1$ & $26.7 \pm 5.4$ & $54.1 \pm 5.4$ & $59.8 \pm 19.6$ & $41.5 \pm 11.0$ & $69.2 \pm 11.1$ \\
\hline (Z)- $\beta$-ocimene* & - & - & - & - & - & $2.8 \pm 1.3$ & $10.5 \pm 2.3$ & $9.4 \pm 3.9$ & $5.7 \pm 1.9$ & $16.3 \pm 2.7$ \\
\hline \multicolumn{11}{|l|}{ Sesquiterepenes*d } \\
\hline $\begin{array}{l}(E)-\beta- \\
\text { caryophyllene }{ }^{*}\end{array}$ & - & - & - & - & - & $2.3 \pm 1.5$ & $5.3 \pm 2.2$ & $6.5 \pm 4.2$ & $1.6 \pm 1.1$ & $9.7 \pm 4.1$ \\
\hline \multicolumn{11}{|l|}{ Homoterpene* } \\
\hline DMNT* & - & - & - & - & - & $14.3 \pm 6.0$ & $13.1 \pm 5.0$ & $15.1 \pm 8.0$ & $4.6 \pm 2.2$ & $23.2 \pm 9.0$ \\
\hline \multicolumn{11}{|l|}{$G L V s^{d}$} \\
\hline $\begin{array}{l}\text { (Z)-3-hexenyl } \\
\text { acetate }\end{array}$ & $4.2 \pm 2.8$ & $4.5 \pm 2.4$ & $5.7 \pm 5.7$ & - & $8.2 \pm 3.7$ & $5.9 \pm 5.9$ & $44.8 \pm 19.7$ & $21.0 \pm 10.1$ & $16.3 \pm 14.8$ & $78.9 \pm 35.6$ \\
\hline \multicolumn{11}{|l|}{ Others } \\
\hline 1-Octene-3-ol* & - & - & - & - & - & - & $3.2 \pm 1.7$ & $2.4 \pm 2.4$ & $2.4 \pm 2.4$ & $4.1 \pm 2.8$ \\
\hline Benzyl alcohol & $1.2 \pm 1.2$ & $7.4 \pm 3.1$ & $4.2 \pm 1.9$ & $8.7 \pm 6.0$ & $6.4 \pm 3.3$ & $2.1 \pm 1.3$ & $1.8 \pm 1.1$ & $3.6 \pm 2.3$ & $1.4 \pm 0.9$ & $2.2 \pm 2.2$ \\
\hline Unknown & $2.3 \pm 1.5$ & $4.1 \pm 2.1$ & $4.8 \pm 3.1$ & $6.1 \pm 3.8$ & $2.4 \pm 2.4$ & $3.9 \pm 2.6$ & $3.6 \pm 1.8$ & $5.2 \pm 3.2$ & $3.6 \pm 2.4$ & $3.6 \pm 3.0$ \\
\hline Nonanal & $5.5 \pm 2.0$ & $13.2 \pm 6.1$ & $11.4 \pm 4.6$ & $11.7 \pm 7.9$ & $14.4 \pm 9.6$ & $13.3 \pm 6.4$ & $13.2 \pm 4.6$ & $15.6 \pm 7.1$ & $11.1 \pm 4.7$ & $15.7 \pm 8.9$ \\
\hline Total $\left.\right|^{* d}$ & $13.7 \pm 4.2$ & $30.1 \pm 7.9$ & $27.8 \pm 2.6$ & $26.5 \pm 13.3$ & $33.2 \pm 10.4$ & $71.3 \pm 15.2$ & $149.5 \pm 30.3$ & $138.4 \pm 41.8$ & $88.4 \pm 17.5$ & $223.0 \pm 46.2$ \\
\hline
\end{tabular}

All data was analyzed using analysis of variance (ANOVA) following transformation of data to meet statistical assumptions. An asterisk (*) designates compounds which increased in their emission with $S$ littoralis herbivory $(p<005)$ and the superscript letter $\left({ }^{d}\right)$ designates compounds that increased in the presence of the grass species $D$. glomerata, $n=5$ 
Table 2 Statistical results for the analysis of VOC emissions from individuals of the focal plant species Trifolium pratense growing in experimental plant communities (Fig. 1). The table shows effects of species richness (1 to 3 plant species), species composition (four levels, Trifolium pratense monoculture (1sp), two species mixture of T. pratense and Geranium pratense, two species mixture of $T$. pratense and Dactylis glomerata and the three species mixture containing T. pratense, G. pratense and D. glomerata) and species identity (with the effect of D. glomerata or G. pratense presence shown in separate columns) on the VOC emission from single individuals of T. pratense. Statistical analyses were performed with absolute amounts $\left(\mathrm{ng} \mathrm{g}^{-1} \mathrm{~h}^{-1}\right)$ and relative amounts (\% of the total VOC emission) of VOCs emitted. The first column in both panels (A and B) denotes the statistical results for the effect of caterpillar herbivory. As the effect of herbivory was the same in these models (where it was always fitted first), the statistical result is only presented once. Interactions between species richness, species composition and herbivory (Spodoptera littoralis caterpillar herbivory) are reported in the column "interactions". Species richness, species composition and species identity (presence or absence of a species) were tested in separate analysis of variance models following transformation of data to meet assumptions of normality and homogeneity of variances (see main text for details). Statistically significant results are depicted in bold with asterisks indicating level of significance $\left({ }^{* *} P<0.001,{ }^{* *} P<0.01\right.$ and $\left.{ }^{*} P \leq 0.05\right)$ and degrees of freedom are provided at the top of the table as $F(d f 1, d f 2), n=5$. See Additional file 2: Table $\$ 4$ for full models

\begin{tabular}{|c|c|c|c|c|c|c|}
\hline \multirow[t]{3}{*}{ (A) } & \multicolumn{6}{|c|}{ Absolute amounts emitted } \\
\hline & \multirow[b]{2}{*}{$\begin{array}{c}\text { Herbivory } \\
(0,1)\end{array}$} & \multirow{2}{*}{$\begin{array}{c}\text { Model } 1 \\
\text { Species } \\
\text { richness } \\
F(1,36)\end{array}$} & \multirow{2}{*}{$\begin{array}{c}\text { Model } 2 \\
\text { Species } \\
\text { composition } \\
F(3,34)\end{array}$} & \multicolumn{2}{|c|}{ Model 3} & \multirow[b]{2}{*}{ Interactions } \\
\hline & & & & $\begin{array}{c}\text { Geranium } \\
\text { pratense } \\
F(1,35)\end{array}$ & $\begin{array}{c}\text { Dactylis } \\
\text { glomerata } \\
\text { F }(1,35)\end{array}$ & \\
\hline Monoterpenes & $* * *$ & $3.1 \mathrm{~ns}$ & $2.8 n s$ & Excl.ns & $8.1 *$ & $n s$ \\
\hline Sesquiterpenes & $* * *$ & $0.3 n s$ & $1.0 \mathrm{~ns}$ & Excl. ns & $2.5 n s$ & ns \\
\hline Homoterpenes & $* * *$ & $0.6 n s$ & $2.4 n s$ & $6.5 *$ & Excl.ns & * \\
\hline Green leaf volatiles & ns & $1.7 n s$ & $3.0 n s$ & Excl.ns & 7.9 * & ns \\
\hline Other volatiles & ns & $0.3 n s$ & $0.1 \mathrm{~ns}$ & Excl. ns & $0.2 n s$ & ns \\
\hline Total & *** & $4.4 n s$ & 4.7 * & Excl. ns & 13.0 ** & ns \\
\hline
\end{tabular}

(B)

Relative proportions emitted

\begin{tabular}{|c|c|c|c|c|c|c|}
\hline \multirow[b]{2}{*}{ Compound Groups } & \multirow[b]{2}{*}{$\begin{array}{c}\text { Herbivory } \\
(0,1)\end{array}$} & \multirow{2}{*}{$\begin{array}{c}\text { Model } 1 \\
\text { Species } \\
\text { richness } \\
F(1,36)\end{array}$} & \multirow{2}{*}{$\begin{array}{c}\text { Model } 2 \\
\text { Species } \\
\text { composition } \\
F(3,34)\end{array}$} & \multicolumn{2}{|c|}{ Model 3} & \multirow[b]{2}{*}{ Interactions } \\
\hline & & & & $\begin{array}{c}\text { Geranium } \\
\text { pratense } \\
F(1,35)\end{array}$ & $\begin{array}{c}\text { Dactylis } \\
\text { glomerata } \\
\text { F }(1,35)\end{array}$ & \\
\hline Monoterpenes & $* * *$ & $0.2 n s$ & $0.1 n s$ & Excl.ns & $0.3 n s$ & ns \\
\hline Sesquiterpenes & $* * *$ & $0.1 n s$ & $0.4 n s$ & Excl.ns & $1.0 n s$ & ns \\
\hline Homoterpenes & $* * *$ & $4.7^{*}$ & 3.6 * & 9.6 * & Excl.ns & * \\
\hline Green leaf volatiles & ns & $0.6 n s$ & $1.5 n s$ & Excl.ns & $3.7 n s$ & ns \\
\hline Other volatiles & $* * *$ & $0.1 n s$ & $0.5 n s$ & $1.0 n s$ & Excl.ns & ns \\
\hline Total & & & & & & \\
\hline
\end{tabular}

When the relative amounts (proportions) of major groups of VOCs in the full blend of $T$. pratense were considered, there were significant changes in the relative amounts of the different compound groups (Fig. 1f-h, Table 2B, for full results see Additional file 2: Table S4B). In the herbivory treatment, monoterpenes increased to $48 \%$ of the full VOC blend compared to only $3 \%$ in non-infested control plants (Fig. 1f-h, Table 2B).

Species richness, species composition and species identity did not affect the relative amounts of monoterpenes, sesquiterpenes, green leaf volatiles and other VOC released from $T$. pratense (Table $2 \mathrm{~B}$, Additional file
2: Table S4B). Only the relative amount of the homoterpene DMNT was affected by species richness, composition and identity (Table 2B) as $T$. pratense plants growing in two- and three-species mixtures emitted lower relative amounts of DMNT than plants growing in monocultures (Fig. 1f-h, Table 2B, Model 1). Similarly, $T$. pratense plants growing together with $G$. pratense emitted significantly lower relative amounts of homoterpenes (DMNT) as compared to other mixtures (Table 2B, Model 3, Additional file 2: Table S4B). There was a significant interaction between herbivory and the presence of G. pratense for homoterpene (DMNT) emission (Table 2B, Model 3, Additional file 2: Table S4B). 


\section{a}

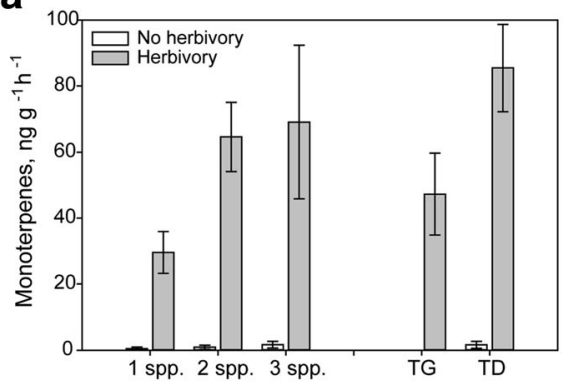

b

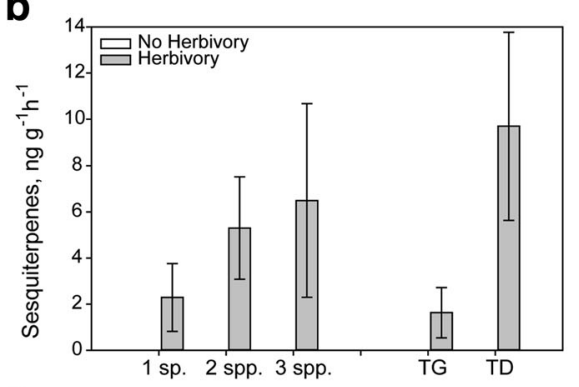

C

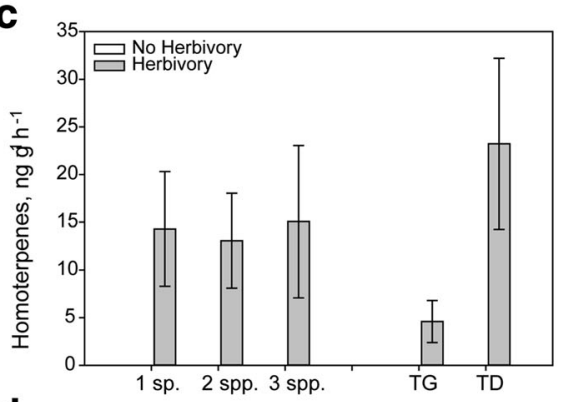

d

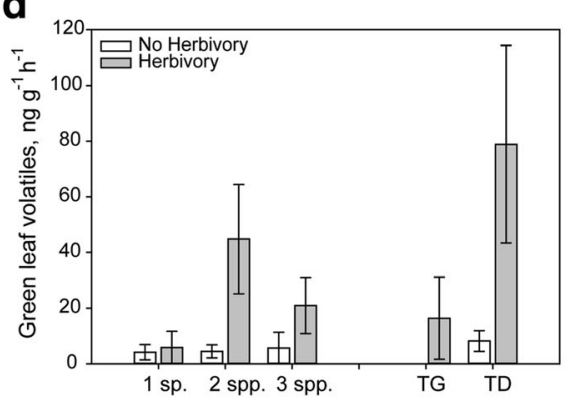

e

${ }^{50} \square^{\text {No Herbivory }}$

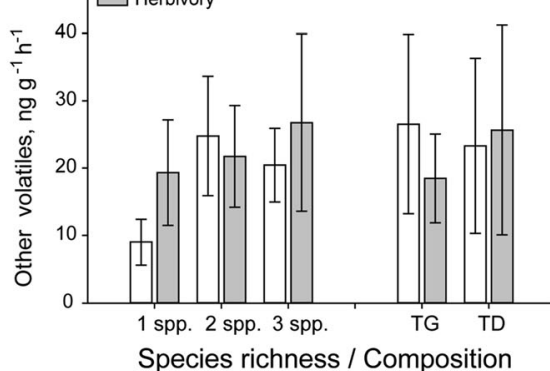

f One Species (Monoculture)

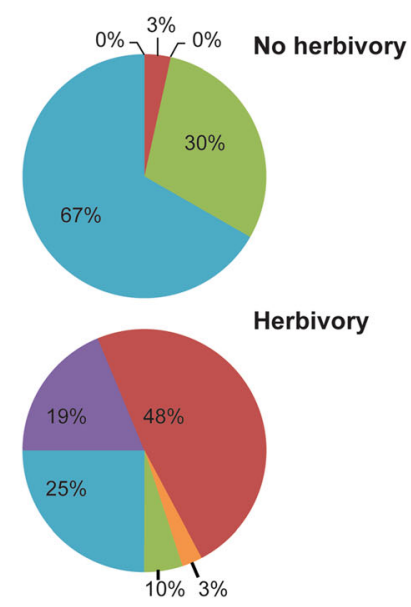

g Two Species Mixtures

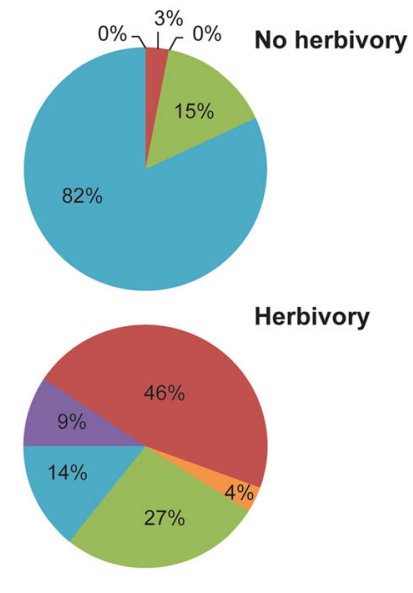

h Three species mixture
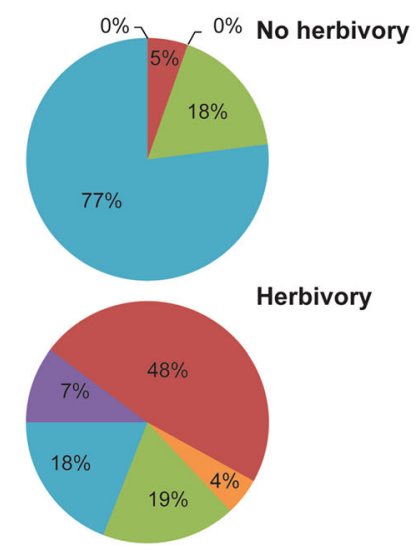

Monoterpenes Sesquiterpenes

- Homoterpenes Others

Green Leaf Volatiles (GLV)

Fig. 1 (See legend on next page.) 
(See figure on previous page.)

Fig. 1 Constitutive and herbivore-induced emission of major groups of volatile organic compounds (VOCs) by single individuals of the focal plant species Trifolium pratense growing in pot communities of differing species compositions. T. pratense plants were either grown in monoculture (1 sp), in two species mixtures with Geranium pratense (TG) or Dactylis glomerata (TD), or in three species mixtures with D. glomerata and G. pratense (3 spp). The focal T. pratense individuals in the experimental communities were either exposed to feeding by three $S$. littoralis caterpillars (Herbivory, grey bars) or had no caterpillars feeding on them (Control, white bars). Values in panels (a, b, c, $\mathbf{d}$ and $\mathbf{e}$ ) represent absolute amounts of VOCs from single T. pratense individuals in $\mathrm{ng} \mathrm{g}^{-1} \mathrm{~h}^{-1}$ and values in the pie charts in panels $(\mathbf{f}, \mathbf{g}$ and $\mathbf{h})$ represent relative amounts of the major groups of VOCs with respect to the full T. pratense odour blend. Homoterpenes were only emitted by plants in the Herbivory treatment. Bars represent means $\pm S E M, n=6$. The results of the statistical analyses are depicted in Table 2

\section{Community VOC emission}

On average twelve different VOCs were emitted from the entire plant communities and this did not change with caterpillar herbivory (glm with Poisson errors, Table 4A, Additional file 3: Table S5A). However, the number of VOCs produced significantly increased with plant species richness, from six compounds in $T$. pratense monocultures to 17 compounds in three-plant-species mixtures (Additional file 3: Table S5A). Similarly, both plant species composition and the identity of the neighboring plant species had a significant effect on the number of VOCs emitted (T. pratense monocultures released significantly fewer VOCs than the two-species mixtures and the three-species-mixture (Additional file 3: Table S5A).

The total amount of VOCs $\left(n g h^{-1} h^{-1}\right)$ emitted from communities was significantly affected by plant species richness, community composition and the identity of the neighboring plant species (Table 3 , statistical results: Table 4A, Models 1-3, for full statistical results see Additional file 3: Table S5A). The total amount of VOCs increased significantly with plant species richness (Tables 3 and 4, Model 1, Additional file 3: Table S5A). For plant species composition (Model 2), the two species mixture of $T$. pratense with $D$. glomerata had higher VOC emissions compared to the two species mixture with G. pratense and the three-species mixture (Tables 3 and 4A, Additional file 3: Table S5A). The presence of D. glomerata in the two species mixture resulted in an increase in total VOC emission while the presence of $G$. pratense had no effect (Tables 3 and 4A, Model 3, Additional file 3: Table S5A). There were no significant interactions between herbivory and species richness, species composition or species identity.

With increasing plant species richness in the plant communities, the emission of all major groups of VOCs except the homoterpenes (DMNT) increased significantly (Table 4A, Fig. 2a-e). Similarly, species composition and neighbor identity altered the emission of all major groups of VOCs except homoterpenes (Table 4A, Fig. 2a-e, Model 2 and 3). The emission of monoterpenes, green leaf volatiles and "other" VOCs was affected by species composition and was highest in the three species mixture and in the two species mixture of $T$. pratense and $D$. glomerata (TD) (Fig. 2a, d, e, and Additional file 3:
Table S5A), while sesquiterpene emission was highest in the three species mixtures and the two species mixture with G. pratense (Fig. 2b, Table 4A). Only the homoterpene emission (DMNT) increased upon caterpillar herbivory and this was true in all different species combinations (Fig. 2c, Table 4A, Additional file 3: Table S5A).

The relative amounts of monoterpenes and homoterpenes in the total VOC blend decreased with increasing plant species richness while the relative amount of sesquiterpenes increased with plant species richness (Fig. 2f-h, Table 4B, Model 1, Additional file 3: Table S5B). The relative amounts of VOCs emitted from the mixtures were also strongly dependent on the composition of the plant mixtures and the identity of the plants (Table 4B, Models 2 and 3, Additional file 3: Table S5B). The presence of G. pratense increased the relative amount of sesquiterpenes, and decreased the relative amounts of homoterpenes (DMNT) (Table 4B, Model 3). The presence of D. glomerata increased the relative amount of monoterpenes and green leaf volatiles in mixtures (Table 4B, Model 3).

\section{Discussion}

In this study we investigated how the identity of neighboring plant species and plant species richness in the community affect the constitutive and herbivore-induced volatile emission from both the focal plant Trifolium pratense (red clover) and entire plant communities containing red clover plants. In an experimental greenhouse study we found that the VOC emission from $T$. pratense was higher in plant species mixtures and was strongly influenced by plant species composition of the surrounding plant community. When growing in communities with the orchard grass Dactylis glomerata, $T$. pratense plants emitted significantly higher amounts of constitutive and herbivore induced volatiles as compared to plants growing together with Geranium pratense, indicating that neighbor species identity strongly impacts the VOC phenotype of T. pratense.

\section{Herbivore induced VOC emission from red clover and the experimental plant communities}

As numerous other studies before, we found a strong effect of insect herbivory of the VOC emission of the plant attacked. S. littoralis feeding resulted in an increased emission of five compounds, 1 -octen-3-ol, $(E)$ - $\beta$-ocimene, 


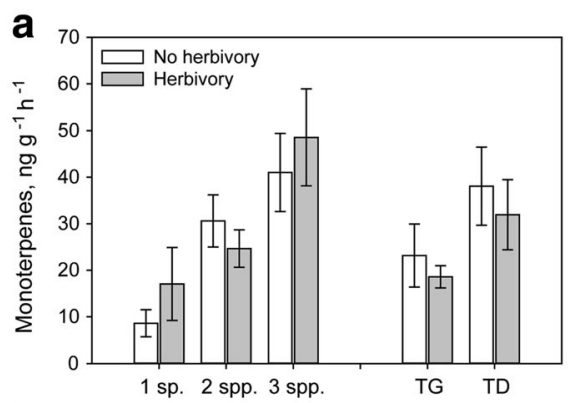

f One species (Monoculture)

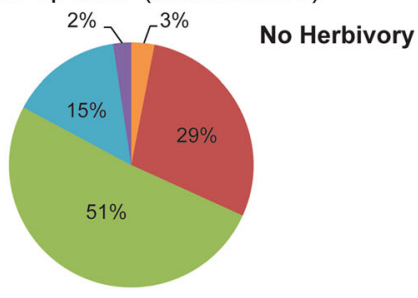

b
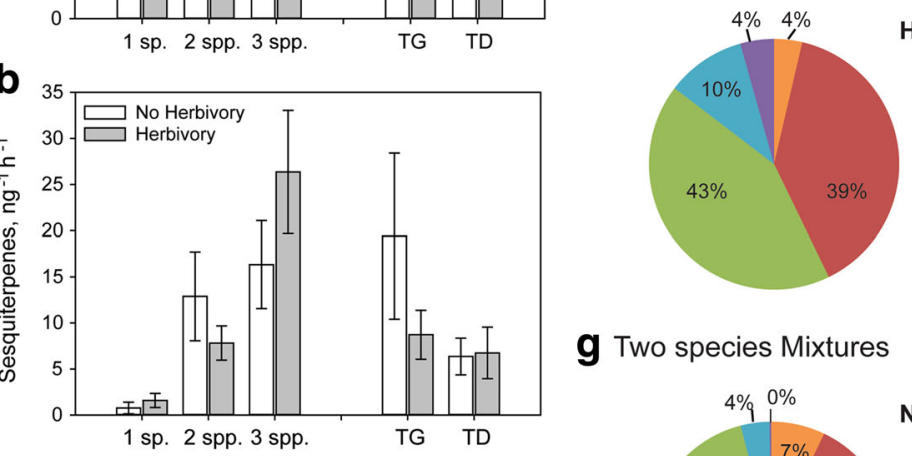

g Two species Mixtures
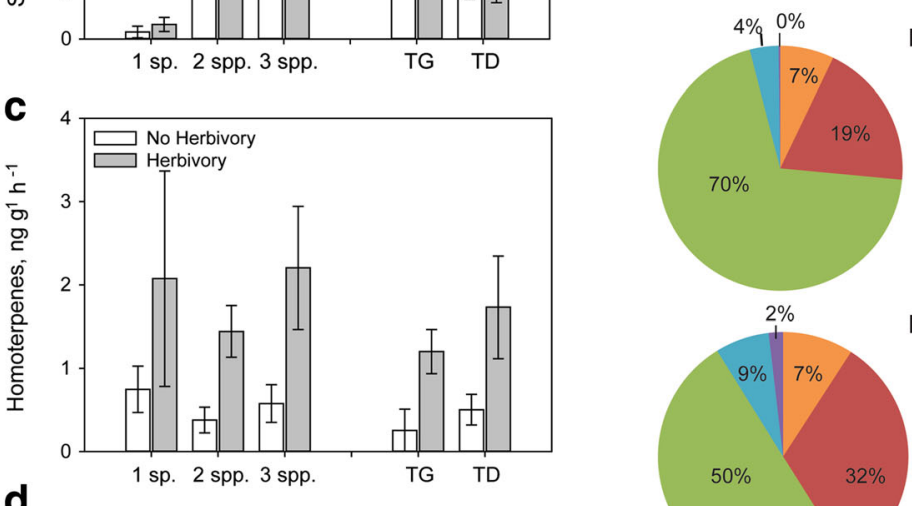

No Herbivory

d
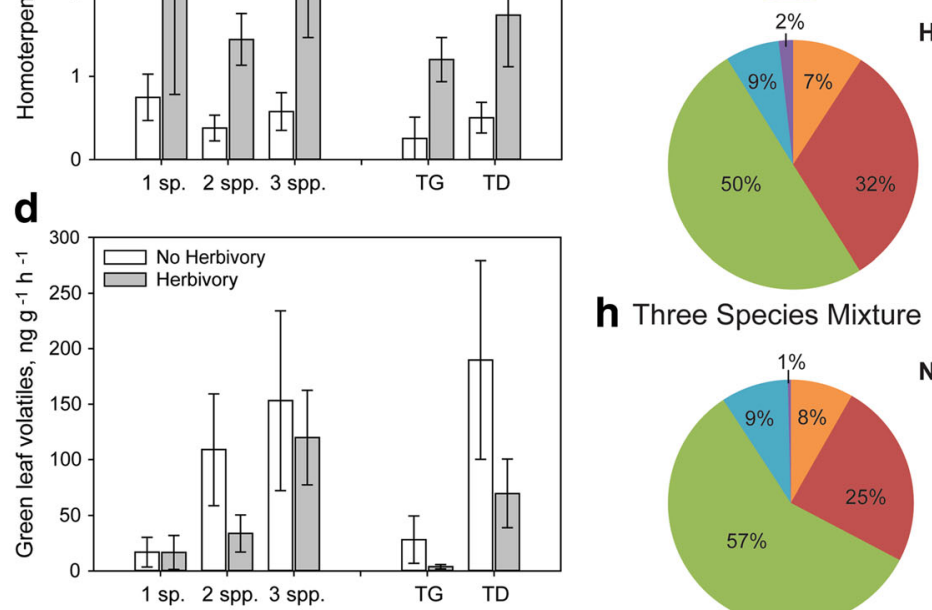

h Three Species Mixture
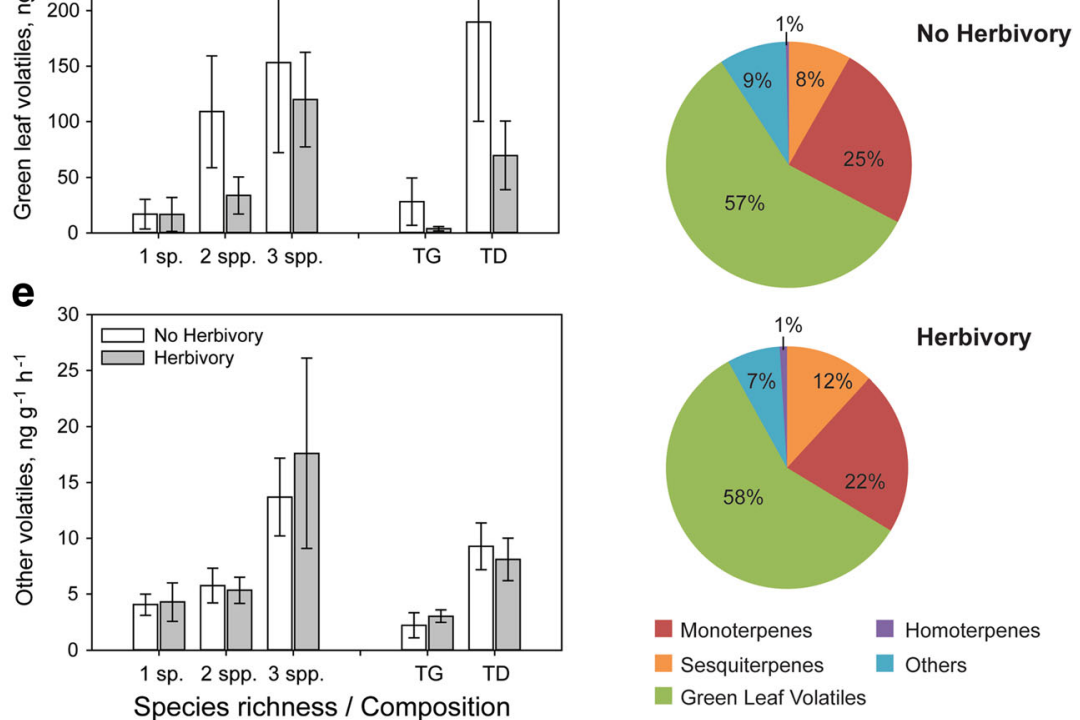

Fig. 2 (See legend on next page.) 
(See figure on previous page.)

Fig. 2 Constitutive and herbivore-induced emission of major groups of volatile organic compounds (VOCs) from experimental plant communities grown in pots in the greenhouse. T. pratense plants were either grown in monoculture (1 sp), in two species mixtures with Geranium pratense (TG) or Dactylis glomerata (TD), or in three species mixtures with D. glomerata and G. pratense (3 spp). Single individuals of the focal plant species T. pratense in the communities were either exposed to feeding by three S. littoralis caterpillars (Herbivory, grey bars) or had no caterpillars feeding on them (Control, white bars). Values in panels ( $\mathbf{a}, \mathbf{b}, \mathbf{c}, \mathbf{d}$ and $\mathbf{e}$ ) represent absolute amounts of VOC emission from experimental plant communities in $\mathrm{ng} \mathrm{g}^{-1} \mathrm{~h}^{-1}$ and values in the pie charts in panels ( $\mathbf{f}, \mathbf{g}$ and $\mathbf{h}$ ) represent relative amounts of the major groups of VOCs with respect to the full T. pratense odour blend. Bars represent means \pm SEM $n=6$. The results of the statistical analyses are depicted in Table 4

Table 3 Constitutive and herbivore-induced VOCs released from entire experimental plant communities grown in pots in the greenhouse. $1 \mathrm{sp}=$ Trifolium pratense monoculture, $\mathrm{TG}=$ two species mixture of $T$. pratense and Geranium pratense, TD = two species mixture of $T$. pratense and Dactylis glomerata (TD), 3 spp (TGD) = three species mixture with T. pratense, D. glomerata and G. pratense. In half of the experimental plant communities, one single T. pratense individual was infested with Spodoptera littoralis caterpillars (Herbviory). Values represent mean VOC emissions $\left(\mathrm{ng} \mathrm{g}^{-1} \mathrm{~h}^{-1}\right) \pm \mathrm{SEM}$ from the experimental plant communities

\begin{tabular}{|c|c|c|c|c|c|c|c|c|c|c|}
\hline \multirow[t]{2}{*}{ Compounds } & \multicolumn{5}{|l|}{ Control } & \multicolumn{5}{|l|}{ Herbivory } \\
\hline & $1 \mathrm{sp} .(\mathrm{T})$ & 2 spp. & 3 spp. (TDG) & TG & TD & $\overline{\mathrm{T}}(1 \mathrm{sp})$. & 2 spp. & 3 spp. (TDG) & TG & TD \\
\hline \multicolumn{11}{|l|}{ Monoterpenes } \\
\hline (Z)- $\beta$-ocimene & $1.5 \pm 0.6$ & $3.9 \pm 1.3$ & $4.4 \pm 1.5$ & $6.5 \pm 2.2$ & $1.3 \pm 0.2$ & $2.2 \pm 1.0$ & $3.4 \pm 0.6$ & $6.1 \pm 1.4$ & $3.9 \pm 0.9$ & $2.7 \pm 0.8$ \\
\hline (E)- $\beta$-ocimene & $6.8 \pm 2.3$ & $18.8 \pm 4.8$ & $23.6 \pm 4.7$ & $7.6 \pm 2.2$ & $30.1 \pm 6.9$ & $13.4 \pm 6.0$ & $17.3 \pm 3.4$ & $33.4 \pm 8.2$ & $11.0 \pm 1.4$ & $24.9 \pm 5.9$ \\
\hline Tricyclene & - & $2.2 \pm 0.9$ & $1.6 \pm 0.7$ & $4.4 \pm 1.3$ & - & - & $1.1 \pm 0.5$ & $2.3 \pm 0.5$ & $2 \pm 0.7$ & - \\
\hline a-Pinene & $0.2 \pm 0.2$ & $1.2 \pm 0.4$ & $1.4 \pm 0.3$ & $2.0 \pm 0.6$ & $0.3 \pm 0.2$ & $0.1 \pm 0.1$ & $0.7 \pm 0.2$ & $1.3 \pm 0.2$ & $1.2 \pm 0.2$ & $0.1 \pm 0.1$ \\
\hline Camphene & - & $0.2 \pm 0.1$ & $0.3 \pm 0.2$ & $0.5 \pm 0.2$ & - & - & $0.1 \pm 0.1$ & $0.3 \pm 0.1$ & $0.1 \pm 0.1$ & - \\
\hline$\beta$-pinene & - & $0.3 \pm 0.1$ & $0.5 \pm 0.2$ & $0.7 \pm 0.2$ & - & - & $0.1 \pm 0.1$ & $0.5 \pm 0.2$ & $0.2 \pm 0.1$ & - \\
\hline Myrcene & - & $1.4 \pm 0.5$ & $3.5 \pm 1.4$ & $1.0 \pm 0.3$ & $1.9 \pm 0.8$ & - & $0.8 \pm 0.4$ & $1.9 \pm 0.6$ & $0.2 \pm 0.2$ & $1.6 \pm 0.8$ \\
\hline Limonene & $0.1 \pm 0.1$ & $2.0 \pm 0.6$ & $4.3 \pm 1.4$ & $0.4 \pm 0.2$ & $3.7 \pm 0.8$ & $0.3 \pm 0.3$ & $0.7 \pm 0.3$ & $2.2 \pm 0.5$ & $0.1 \pm 0.1$ & $1.3 \pm 0.6$ \\
\hline Linalool & - & $0.5 \pm 0.3$ & $1.4 \pm 0.4$ & $0.2 \pm 0.2$ & $0.9 \pm 0.6$ & $1.1 \pm 1.0$ & $0.6 \pm 0.4$ & $0.7 \pm 0.4$ & - & $1.4 \pm 0.7$ \\
\hline \multicolumn{11}{|l|}{ Sesquitepene } \\
\hline (E)- $\beta$-Caryophyllene* & $0.1 \pm 0.1$ & $3.5 \pm 1.8$ & $3.8 \pm 1.0$ & $5.9 \pm 3.3$ & $1.1 \pm 0.4$ & $1.6 \pm 0.8$ & $3.0 \pm 0.6$ & $9.7 \pm 2.1$ & $3.5 \pm 0.9$ & $2.5 \pm 0.9$ \\
\hline (E)- $\beta$-Farnesene & - & $2.2 \pm 1.4$ & $1.8 \pm 1.2$ & $4.3 \pm 2.6$ & - & - & $0.4 \pm 0.3$ & $3.7 \pm 2.0$ & $0.8 \pm 0.5$ & - \\
\hline cucurmene & - & $1.7 \pm 1.4$ & $0.5 \pm 0.2$ & $3.4 \pm 2.7$ & - & - & $1.3 \pm 1.0$ & $1.1 \pm 0.5$ & $2.4 \pm 1.7$ & - \\
\hline Germacrene D & - & $2.8 \pm 1.6$ & $4.2 \pm 2.9$ & $5.7 \pm 2.8$ & - & - & $1.2 \pm 0.4$ & $5.9 \pm 1.4$ & $2.1 \pm 0.4$ & $0.1 \pm 0.1$ \\
\hline$(\mathrm{E}, \mathrm{E})$ - $\mathrm{a}$-Farnesene & $0.7 \pm 7$ & $2.7 \pm 1.2$ & $6.1 \pm 2.2$ & $0.1 \pm 0.1$ & $5.2 \pm 1.8$ & - & $1.9 \pm 1.1$ & $6.1 \pm 2.4$ & - & $4.2 \pm 1.9$ \\
\hline \multicolumn{11}{|l|}{ Homoterpenes } \\
\hline DMNT* & $0.8 \pm 0.3$ & $0.4 \pm 0.2$ & $0.6 \pm 0.2$ & $0.3 \pm 0.3$ & $0.5 \pm 0.2$ & $2.1 \pm 1.3$ & $1.5 \pm 0.3$ & $2.2 \pm 0.7$ & $1.2 \pm 0.3$ & $1.7 \pm 0.6$ \\
\hline \multicolumn{11}{|l|}{ GLVs } \\
\hline (Z)-3-Hexenyl acetate & $17 \pm 13$ & $109 \pm 50$ & $153 \pm 81$ & $28 \pm 21$ & $190 \pm 90$ & $17 \pm 15$ & $34 \pm 17$ & $120 \pm 43$ & $4 \pm 2$ & $70 \pm 31$ \\
\hline \multicolumn{11}{|l|}{ Other volatiles } \\
\hline 1-Octen-3-ol & - & $1 \pm 0.3$ & $2.6 \pm 0.7$ & - & $2.0 \pm 0.3$ & - & $0.9 \pm 0.4$ & $2.2 \pm 0.6$ & - & $1.9 \pm 0.4$ \\
\hline Octly-acetate & - & $0.2 \pm 0.1$ & $0.5 \pm 0.2$ & - & $0.4 \pm 0.2$ & $0.5 \pm 0.4$ & $0.7 \pm 0.2$ & $0.3 \pm 0.2$ & $0.7 \pm 0.4$ & $0.6 \pm 0.2$ \\
\hline Nonanal & $1.8 \pm 0.7$ & $1.4 \pm 0.4$ & $1.6 \pm 0.7$ & $0.9 \pm 0.5$ & $1.9 \pm 0.6$ & $1.9 \pm 1.1$ & $1.3 \pm 0.3$ & $1.6 \pm 0.6$ & $1.6 \pm 0.5$ & $1.0 \pm 0.3$ \\
\hline Benzyl alcohol & $1.9 \pm 1.0$ & $2.5 \pm 1.1$ & $8.1 \pm 2.8$ & $1.1 \pm 0.7$ & $4.0 \pm 1.9$ & $1.0 \pm 0.7$ & $1.8 \pm 0.8$ & $12.2 \pm 7.7$ & $0.4 \pm 0.3$ & $3.5 \pm 1.5$ \\
\hline Unknown & $0.5 \pm 0.2$ & $0.3 \pm 0.1$ & $0.7 \pm 0.2$ & $0.3 \pm 0.1$ & $0.3 \pm 0.1$ & $0.9 \pm 0.5$ & $0.5 \pm 0.2$ & $0.6 \pm 0.2$ & $0.4 \pm 0.2$ & $0.6 \pm 0.3$ \\
\hline MESA & - & $0.4 \pm 0.3$ & $0.3 \pm 0.3$ & - & $0.8 \pm 0.6$ & - & $0.3 \pm 0.2$ & $0.8 \pm 0.5$ & - & $0.6 \pm 0.3$ \\
\hline Total & $31 \pm 14$ & $159 \pm 55$ & $225 \pm 90$ & $73 \pm 35$ & $244 \pm 96$ & $42 \pm 20$ & $73 \pm 22$ & $215 \pm 50$ & $35 \pm 6$ & $118 \pm 40$ \\
\hline
\end{tabular}

All data was analyzed using analysis of variance (ANOVA) following transformation of data to meet assumptions of normality and homogeneity of variances. An asterisk $\left(^{*}\right)$ designates compounds which increased in their emission from the plant community when one individual of the focal plant $T$ pratense within the community was infested with $S$ littoralis caterpillars $(p<0.05), n=5$ 
Table 4 Statistical results for the analysis of VOC compound group emissions from experimental plant communities grown in pots in the greenhouse (Fig. 2). The table shows effects of species richness (1 to 3 plant species), species composition (four levels, Trifolium pratense monoculture (1sp), two species mixture of T. pratense and Geranium pratense, two species mixture of T. pratense and Dactylis glomerata and the three species mixture containing T. pratense, G. pratense and D. glomerata) and species identity (with the effect of D. glomerata or G. pratense presence shown in separate columns) on the VOC emission from experimental plant communities. Statistical analyses were performed with absolute amounts (ng $\mathrm{g}^{-1} \mathrm{~h}^{-1}$ ) and relative amounts (\% of the total VOC emission) of VOCs emitted. The first column in both panels (A and B) denotes the statistical results for the effect of caterpillar herbivory. As the effect of herbivory was the same in these models (where it was always fitted first), the statistical result is only presented once. Interactions between species richness, species composition and herbivory (Spodoptera littoralis caterpillar herbivory in one individual of the focal plant species T. pratense in each community) are reported in the column "interactions". Species richness, species composition and species identity (presence or absence of a species) were tested in separate analysis of variance models following transformation of data to meet assumption of normality (see text for details). Statistically significant results are depicted in bold with asterisks indicating level of significance ( ${ }^{* *} \mathrm{P}<0.001,{ }^{* *} \mathrm{P}<0.01$ and ${ }^{*} \mathrm{P} \leq 0.05$ ) and degrees of freedom are provided at the top of the table as $F(d f 1, d f 2), n=5$. See Additional file 3: Table 55 for full models

\begin{tabular}{|c|c|c|c|c|c|c|}
\hline \multirow[b]{3}{*}{ Comnound Grouns } & \multicolumn{6}{|c|}{ Absolute amounts emitted } \\
\hline & \multirow[b]{2}{*}{$\begin{array}{c}\text { Herbivory } \\
(0,1)\end{array}$} & \multirow{2}{*}{$\begin{array}{c}\text { Model } 1 \\
\text { Species } \\
\text { richness } \\
F(1,37)\end{array}$} & \multirow{2}{*}{$\begin{array}{c}\text { Model } 2 \\
\text { Species } \\
\text { composition } \\
F(3,35)\end{array}$} & \multicolumn{2}{|c|}{ Model 3} & \multirow[b]{2}{*}{ Interactions } \\
\hline & & & & $\begin{array}{c}\text { Geranium } \\
\text { pratense } \\
F(1,36)\end{array}$ & $\begin{array}{c}\text { Dactylis } \\
\text { glomerata } \\
\text { F }(1,36)\end{array}$ & \\
\hline Monoterpenes & $n s$ & $21.8 * * *$ & $8.8^{* * *}$ & 5.6 * & 19.1 *** & $n s$ \\
\hline Sesquiterpenes & ns & $38.9 * * *$ & $16.6 * * *$ & $37.9 * * *$ & $9.2 * *$ & $n s$ \\
\hline Homoterpenes & $* * *$ & $0.0 n s$ & $0.7 n s$ & $0.3 n s$ & Excl.ns & ns \\
\hline Green leaf volatiles & ns & $11.4^{* *}$ & $8.4^{* * *}$ & Excl. ns & $25.7^{* * *}$ & ns \\
\hline Other volatiles & ns & $15.3^{* *}$ & $15.7^{* * *}$ & Excl. ns & $41.7^{* * *}$ & $n s$ \\
\hline Total & $n s$ & $20.4^{* * *}$ & $9.8^{* * *}$ & Excl.ns & $27.4^{* * *}$ & ns \\
\hline \multirow[b]{3}{*}{ Comnound Graunc } & \multicolumn{6}{|c|}{ Relative proportions emitted } \\
\hline & & Model 1 & Model 2 & Moc & lel 3 & \\
\hline & $\begin{array}{l}\text { Herbivory } \\
(0,1)\end{array}$ & $\begin{array}{c}\text { Species } \\
\text { richness } \\
F(1,37)\end{array}$ & $\begin{array}{c}\text { Species } \\
\text { composition } \\
F(3,35)\end{array}$ & $\begin{array}{c}\text { Geranium } \\
\text { pratense } \\
F(1,36)\end{array}$ & $\begin{array}{c}\text { Dactylis } \\
\text { glomerata } \\
\text { F }(1,36)\end{array}$ & Interactions \\
\hline Monoterpenes & $n s$ & $6.1^{*}$ & $4.6 *$ & Excl. ns & $13.5^{* *}$ & $n s$ \\
\hline Sesquiterpenes & ns & $8.1^{*}$ & $18.5^{* * *}$ & $34.6 * * *$ & Excl. ns & ns \\
\hline Homoterpenes & $* *$ & 14.4 ** & $5.7^{* *}$ & 4.8 * & 10.0 ** & ns \\
\hline Green leaf volatiles & ns & $4.1 \mathrm{~ns}$ & $5.9 * *$ & Excl. ns & $17.1 * * *$ & ns \\
\hline Other volatiles & ns & $4.0 n s$ & $2.6 \mathrm{~ns}$ & $3.9 \mathrm{~ns}$ & Excl.ns & ns \\
\hline Number of Volatiles & ns & 7.0 ** & 4.0 ** & 5.2 * & 4.7 * & \\
\hline
\end{tabular}

(Z)- $\beta$-ocimene, $(E)$ - $\beta$-caryophyllene and 4,8-dimethyl-1,3,7nonatriene (DMNT) of T. pratense plants. These VOCs are emitted by a wide range of plant species and some of them have been shown to attract herbivore natural enemies [5, 44]. 1-octen-3-ol was so far mostly found to be released by pathogenic or endophytic fungi (e.g. [14, 55, 61]) however, recent studies have shown that this compound is also emitted from a number of legume species such as Vigna unguiculata (cowpea, [2]), Medicago truncatula [38], Trifolium pratense [34] and Lotus japonicus [46]. The slightly higher levels of 1-octen-3-ol measured in the headspace of herbivore-infested $T$. pratense plants may be due to herbivore-inflicted damage of fungal tissue present inside/on the foliage of red clover plants. Monoterpenes showed the highest relative increase in emission after caterpillar herbivory and emission levels increased from an average of 3 to $47 \%$ across all diversity levels. $(E)$ - $\beta$-Ocimene was the dominant monoterpene emitted from red clover, as reported previously [34, 35]. In contrast, in our study, methyl salicylate (MeSA) was not detected in the headspace of $T$. pratense plants. This could be either due to genotype-specific effects on VOC emission, or simply due to shorter VOC collection periods (too short to trap detectable amounts of MeSA) in our study as compared to earlier VOC collections by 
Kigathi et al. [34, 35]. However, Kigathi et al. [35] also showed that plants growing in intra- or inter-specific competition emitted lower amounts of MeSA than plants growing alone, which could also explain why we did not detect this compound here.

Of the five compounds that increased in VOC emission with herbivory in $T$. pratense plants, two compounds, DMNT and $(E)$ - $\beta$-caryophyllene, also significantly increased in the headspace of the plant communities containing only one herbivore infested $T$. pratense plant. This was measurable despite the fact that the two compounds were emitted in relatively low amounts as compared to other VOCs emitted from the communities such as (Z)-3-hexenylacetate, $(E)$ - $\beta$-ocimene and the aromatic compound benzyl alcohol. As specifically DMNT is indicative of insect herbivore damage (e.g. [4, 17]) this compound may function as a valuable information telling host seeking predatory insects in complex plant communities where their prey is located. Future experiments in natural grassland communities have to validate whether this assumption holds true.

As a caveat, plant species richness in our study only ranged from 1 to 3 species and there we focused on $T$. pratense, i.e. we did not investigate monocultures of $D$. glomerata or G. pratense. Consequently, plant species richness effects were confounded with effects of plant species composition and the presence of particular neighboring species of $T$. pratense. We partly accounted for this by using three different statistical models, each testing for one particular effect (species identity, species composition and species richness), and compared which one explained most of the variance in the VOC data. However, despite the shortcomings of the design for detecting plant diversity effects independent of plant species composition or identity, the effects of plant species richness we found are significant, as they emphasize that increased complexity of the plant community and hence an increasing number of plant-plant interactions will affect plant VOC emission and the VOC blend that a searching insect herbivore is exposed to.

\section{Plant species richness-, species composition- and neighbor identity effects on Trifolium pratense VOC emission}

Increasing plant species richness in communities is known to not only introduces plant interspecific competition, but also changes a number of other parameters potentially affecting plant growth such as the interaction of plants with soil microbes or aboveground and belowground animals, or the availability of nutrients due to changes in $\mathrm{C}, \mathrm{N}$ and $\mathrm{P}$ cycling [60]. Plants have been shown to respond to increasing plant diversity by adjusting morphological traits such as size, C:N ration or module number, as well as physiological traits such as foliar $13 \mathrm{C}$ values [8]. We found that VOC emissions of $T$. pratense increased with increasing plant species richness in the experimental plant communities; however, the relative amounts of individual VOCs in the blend did not change. Monoterpenes, for example, were emitted in relative amounts of $48 \%$ across all diversity levels.

The effect of plant species composition on $T$. pratense VOC emission was stronger than the effect of plant species richness, and the most striking changes in VOC emission were observed in the communities containing the orchard grass Dactylis glomerata. In these communities, significantly more VOCs were emitted from T. pratense. Thus, $T$. pratense responded to the increase in the competitive environment by upregulating its VOC emission. Recent evidence from the literature supports the finding that competitive interactions between plants can substantially change VOC emissions even at the constitutive level ([31, 47] and references therein). In an earlier study we already showed that competitor identity significantly changed the VOC emission from $T$. pratense [35].In that study, T. pratense plants growing with conspecifics also emitted a lower amount of VOCs than plants growing in inter-specific competition with the orchard grass D. glomerata, and this was even true when plants had contact only aboveground, i. e. where leaves were in contact, or only belowground, i. e. root contact [35]. In contrast to D. glomerata, the presence of G. pratense did not influence the VOC emission of $T$. pratense plants. In two-species mixtures with G. pratense, the abundance of VOCs in the single plant headspace was comparable to $T$. pratense plants growing in monocultures.

The proximate underlying mechanisms of these VOC emission changes are not yet clear. Neighbor-mediated changes in abiotic conditions such as water, light and nutrient availability may have affected $T$. pratense VOC emission as these factors have been shown before to up- or down-regulate plant VOC emission [20, 32]. For example, it is likely that in communities with $D$. glomerata $T$. pratense plants experience stronger competition [25]. Schmelz et al. [52] found that nitrogen deficiency increased the emission of sesquiterpenes from maize plants, while Gouinguene \& Turlings [20] reported a decrease in VOC emission from maize under low nutrient conditions. There is also the possibility of VOC catabolism (breakdown of VOCs) within T. pratense individuals that can modify overall VOC emission (Reviewed by [45] TIPS) and should thus be integrated in future considerations on overall carbon flux in plants. Alternatively, the interactions between $T$. pratense and other organisms might be changed, with consequences for VOC emissions. Ballhorn et al. [1] showed that rhizobia influence HIPV emission of lima bean plants. As $T$. pratense in our study is also a legume associated with rhizobia, it is conceivable that changes in VOC emission in different experimental plant communities are an 
indirect effect of rhizobial densities in the roots mediated by competitive interactions with other plant species in the community [51]. Recent studies have also shown that VOC emission in plants can be induced via mycelial networks of mycorrhizal fungi transferring chemical cues from neighboring plants (reviewed by [27]). Further sources of variation for focal plant VOC emission are discussed in a recent review by Meiners [41].

\section{Species composition and plant species richness effects on plant community VOC emission}

One of the striking results of our experiment is the effect of plant species richness and plant species composition on the VOC emission of the entire plant community. Here, the effect of plant species richness on community VOC emission was even stronger than that of plant species composition. First, the number of VOCs in the headspace increased with increasing plant species richness, which in itself is not very surprising given that each plant species is capable of emitting a specific blend of VOCs (including species-specific and non-species-specific VOCs). However, to our knowledge, this study is the first to demonstrate that VOC complexity in the headspace of plant communities increases with increasing plant species richness. Second, the total amount of VOCs in plant species mixtures also increased in comparison to T. pratense monocultures. Similar to the case of $T$. pratense VOC emissions, there were strong effects of plant species composition on the VOC blend of the entire plant community. The T. pratense- D. glomerata mixture (TD) emitted higher amounts of VOCs than the T. pratense - G. pratense (TG) mixture, and the composition of the blend in the headspace also depended on which plant species grew together with $T$. pratense. As in the case of emissions by single $T$. pratense it is not clear if the proximate mechanism for plant community VOC emission involves alterations in abiotic factors such as light, water and nutrients (reviewed by [31]).It is also possible that T. pratense plants as low VOC emitters growing in mixtures with $D$. glomerata adsorb excessive VOCs from the environment (e.g. released by high VOC emitters such as D. glomerata) and release them again [24, 45], leaving the erroneous impression that there is a higher production of VOCs in T. pratense growing in competition with the grass species. Future studies have to achieve further mechanistic understanding of the VOC emission patterns observed in our study. Although community headspace measurements could not exclude volatiles from the soil/roots, we were comparing detectable changes with diversity of headspace volatiles. This would mean that even if some emissions are from soils/ roots and changes with diversity at detectable amounts, they still have potential ecological significance in the field as they potentially affect the behavior of both herbivorous insects and their natural enemies.

\section{Ecological consequences}

Herbivore-induced plant volatiles (HIPVs) represent phenotypically plastic responses of plants to damage by insect herbivores that can result in changes in insectplant interactions at the community level (reviewed by $[47,54])$. HIPVs attract natural enemies of insect herbivores [44], but it is still unclear how this biological control functions in complex plant communities [9]. Parasitoids could require more time to find their host-plant complex in mixtures compared to monocultures, especially when neighboring plant species release similar VOC compounds [19]. However, the few studies that have examined this found little effect of increasing odor complexity on host searching efficiency of predators and parasitoids [11, 48, 59].

Natural enemies can use ubiquitous HIPVs in a ratio-specific way and may thus discriminate between different plant species, or between herbivore-wounded and healthy plants, based on the relative amounts of different VOCs investigated [5]. The analysis of headspace affects is complicated because insects do not necessarily react to the dominant compounds in the VOC profile. For example, it has recently been shown that a braconid parasitic wasp (Glyptapanteles liparidis) parasitizing generalist gypsy moth caterpillars is attracted to minor nitrogenous compounds released from black poplar trees from the site of actual caterpillar damage, rather than to major HIPVs such as DMNT, (E)- $\beta$-ocimene or sesquiterpenes[4].

In our study the highest changes in absolute amounts of VOCs in the focal plant were recorded for $(E)$ - $\beta$-ocimene, and at the community level for DMNT and $(E)$ - $\beta$-caryophyllene. The latter two compounds were emitted in relatively low amounts, but they were the most characteristic compounds indicative of herbivore damage. Additional VOC emissions from the single herbivore-infested $T$. pratense individuals in the community of six plants were sufficient to change the bouquet of the whole plant community, and may thus also be enough to attract natural enemies.

Overall, the differences in VOC emissions detected by comparing the emission of individual plants to emissions of the plant community level suggests that it is necessary to not only measure plants in isolation, but also measure community VOC emissions. DMNT was only emitted from the experimental plant communities containing a caterpillar-damaged red clover plant, and thus this compound may be a reliable indicator for the presence of insect herbivores also in complex plant communities. VOCs produced by plant neighbors (competitors) have been proposed to have a masking, repellent, enhancing or no (neutral) effect depending on insect sensitivity to the VOCs from non-host plants $[23,53]$. In a study by Waschke et al. [59] parasitoids of the weevil Mecinus pascuorum feeding on ribwort plantain were not affected by additional 
non host-plant VOCs, but preferred the odor blend released from the host-host-plant system over the more complex blend. To ultimately elucidate the role of neighbor-released VOCs for parasitoid and insect natural enemy attraction to a focal plant, further sophisticated behavioral studies under lab and field conditions are needed.

The question arises why plants should change their VOC emission when they grow together with other plant species in a community. $T$. pratense plants growing in monocultures always emitted lower amounts of constitutive and herbivore induced VOCs than individuals growing in plant species mixtures. When the VOC emission of all plant individuals in the experimental plant communities was measured, $T$. pratense monocultures also exhibited the lowest overall emissions. One possible explanation is that plants growing in a highly complex and competitive plant community with a more complex and intensive odor environment need to increase their VOC emission, to be sensed by beneficial insects such as pollinators and parasitoids or predators of their natural enemies. In addition, when plants are attacked by herbivores, they become competitively weaker, making it even more pressing to call for herbivore natural enemies. Field studies testing the effectiveness of parasitoid attraction in simple and complex odor environments are needed to test this hypothesis.

\section{Conclusion}

Our study revealed complex changes in the blend of VOCs released from plant communities depending on the number of plant species and the plant species composition within the community with and without insect herbivores. The challenge for future experiments is to reveal the underlying mechanisms leading to neighbor-related changes in focal plant VOC emission and if these changes convey a fitness advantage for the plant. Whether plant community and plant species richness inflicted changes in VOC emission affect the infochemical network involved in attraction of herbivores, herbivore enemies and pollinators in plant communities is also worth detailed investigation.

\section{Methods}

\section{Plant and insect material}

Three common Eurasian grassland species, the legume Trifolium pratense L., the forb Geranium pratense L. and the grass Dactylis glomerata L. were grown from seeds (Rieger Hofmann, Blaufelden-Raboldshausen, Germany) in the greenhouse, planted in plug trays filled with commercially available soil (TonKultur Subtrat ${ }^{\circ}$, Klassman Deilmann, Geeste, Germany). After 3 weeks, the seedlings were transplanted in groups of six individuals in pots with a diameter of $13 \mathrm{~cm}$ filled with commercially available potting soil TonKultur Subtrat ${ }^{\circ}$, mixed with sand at a ratio of 2:1. For 4 weeks the plants were maintained in the greenhouse (day: night temperatures, $20-22^{\circ} \mathrm{C}: 18-20^{\circ} \mathrm{C} ; 30-55 \%$ humidity, $16 \mathrm{~h}$ light, photosynthetically active radiation approximately $180 \mu \mathrm{mol} \mathrm{m}-2 \mathrm{~s}-1$ at plant height). By the time the experiment started, the focal plant species $T$. pratense started budding. The aboveground biomass of the plants in the different experimental plant communities is shown in an additional graph (see Additional file 1). The three species we selected for the experiments also naturally occur together in Central European grasslands of different diversity levels (Stein et al. 2010; Unsicker et al. 2006).

Spodoptera littoralis Boisd. (Lepidoptera: Noctuidae) caterpillars were hatched from eggs (Syngenta, Basel, Switzerland) and reared on agar-based artificial medium [17] at $23-25^{\circ} \mathrm{C}$ with a $16 / 8 \mathrm{~h}$ light/dark cycle until they reached the 3rd larval instar.

\section{Plant diversity and herbivory treatments}

The effect of plant diversity on VOC emission from the focal plant $T$. pratense and plant communities at different diversity levels was tested by varying plant species richness from one to three species. The monoculture consisted of only $T$. pratense $(\mathrm{T})$, the two species mixtures had two sets: one mixture containing $T$. pratense and $D$. glomerata (TD), and the other $T$. pratense and G. pratense (TG); all three plant species were part of the three species mixture (TDG). The total number of different plant communities was therefore four. Each pot contained six plant individuals (monoculture: six of the same species, two species mixture: three of each species, three species mixture: two of each species) Fig. 3.

From each community a focal red clover plant was selected to which the herbivory treatment and VOC collections were applied. We always selected one of the outer plants in the pot to simplify bagging, herbivore application and VOC collections. Half of all pots in each diversity level were infested with herbivores $(\mathrm{H})$ and the other half functioned as the non-infested control group (C). In the herbivory treatment $(\mathrm{H})$, three Spodoptera littoralis caterpillars previously starved for $8 \mathrm{~h}$ were allowed to feed on the focal red clover plant for $24 \mathrm{~h}$ before the start of VOC collection. To restrict caterpillar feeding to the focal plant, these plants were enclosed in open top polyethylene terephthalate (PET) bags. The PET bags were very slippery and effectively prevented escape of $S$. littoralis caterpillars. For experimental consistency focal plants in the control group were also enclosed with a PET bag. In the greenhouse, the pots were grouped in six blocks, each block containing every treatment and plant composition level $(2 \times 4=8$ plants in two trays). In total there were $6 \times 8=$ 48 pots in the experiment. The position of pots within a block was randomized. Because of the high workload involved in measuring VOCs, the herbivory treatment and subsequent VOC collection were staggered over a period of 6 days, i.e. every day one block of plants was exposed to 
a
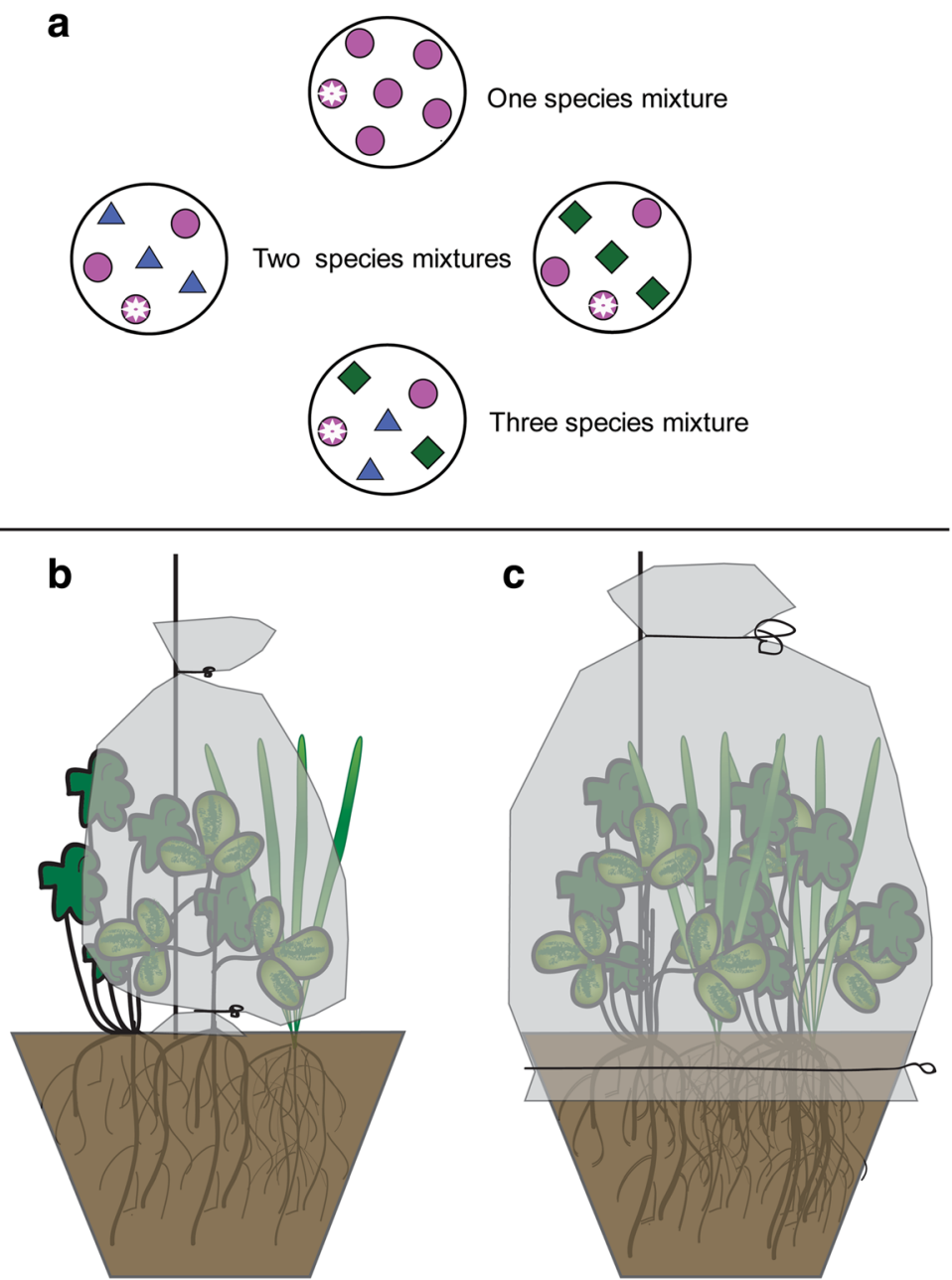

Fig. 3 Graphical illustration of the planting scheme in the greenhouse (a) and the PET bag installation for VOC collections from single Trifolium pratense individuals (b) and entire experimental plant communities. (c) Different shapes represent different species, circles represent T. pratense, triangles Geranium pratense and squares are Dactylis glomerata plants Circles with an asterisk represent the individual of the focal plant species T. pratense that was sampled for volatile emission

caterpillars and VOCs were collected the following day. For VOC collections, plants of one block were transferred from the greenhouse to a climate chamber $\left(23^{\circ} \mathrm{C}, 16 / 8 \mathrm{~h}\right.$ light and dark cycles, $60 \%$ relative humidity).

\section{VOC collection and analysis}

Single plant: VOC emission of one T. pratense individual in each experimental plant community was measured using a push-pull system. Single plants were enclosed with PET cooking bags $(30 \mathrm{~cm} \times 60 \mathrm{~cm}$, volume $28.89 \pm 0.47$ L, Toppits ${ }^{\circ}$ Bratschlauch, Melitta, Minden, Germany) supported by rods of stainless steel (Fig. 3). Since the bag was tied at both ends using PET strips to form an ellipsoid, the bags had an approximate volume of $28.89 \pm 0.47 \mathrm{~L}$. Compressed air (from an in-house system in the greenhouse) entered the system after passing through an activated charcoal filter on the lower side of the plant at a flow rate of $4.0 \pm 0.5$
$1 /$ min and was pulled out at the top through an adsorbent super-Q filter (Alltech, FL, USA), using vacuum at the rate of $2 \pm 0.5 \mathrm{l} / \mathrm{min}$ for $1 \mathrm{~h}$. Before the initiation of VOC sampling, charcoal-filtered clean air was flushed though the collection system for $15 \mathrm{~min}$ to remove VOCs resulting from handling of the plants during setup of the apparatus. All volatile collections were performed between 1000 and $1300 \mathrm{~h}$.

Plant community: After VOCs were collected from the headspace of individual $T$. pratense plants, VOCs from the headspace of the entire plant communities were collected by enclosing all plants in each pot with PET cooking bags of size $30 \mathrm{~cm} \times 80 \mathrm{~cm}$ (approximate volume of $37.7 \pm 0.47 \mathrm{~L}$, Fig. 3). VOCs were collected for $1 \mathrm{~h}$ as described above. After VOC collection the traps were eluted with $150 \mu \mathrm{l}$ hexane containing nonylacetate as the internal standard (concentration: $4 \mathrm{ng} / \mu \mathrm{l}$; Sigma-Aldrich, Germany). As for VOC collections from the headspace 
of entire plant communities, PET foil was wrapped around the pots (Fig. 3), it is possible that soil-derived VOCs were also trapped.

VOCs were analyzed using an Agilent 6890 Series gas chromatograph (Agilent, Santa Clara, CA, USA), with helium as the carrier gas; the outlet of the column (DB-5MS, $30 \mathrm{~m} \times 0.25 \mathrm{~mm} \times 0.25 \mu \mathrm{m}$ film, $\mathrm{m}$, J \& W Scientific, Folsom, CA, USA) was coupled to an Agilent $5973 \mathrm{~N}$ quadrupole mass detector. Parameters for electron impact sample ionization were as follows: interface temperature, $280^{\circ} \mathrm{C}$; repeller, $30 \mathrm{~V}$; emission, $34.6 \mu \mathrm{A}$; electron energy, $70 \mathrm{eV}$; source temperature, $230^{\circ} \mathrm{C}$. The chromatographic conditions were as follows: splitless injection at $220^{\circ} \mathrm{C}$, initial oven temperature, $40^{\circ} \mathrm{C}$ for 3 min, increased at $5^{\circ} \mathrm{C} / \mathrm{min}$ to $210^{\circ} \mathrm{C}$ followed by an increase of $60^{\circ} \mathrm{C} / \mathrm{min}$ to $300^{\circ} \mathrm{C}$ and held for $2 \mathrm{~min}$. We used commercially available authentic standards (Sigma Aldrich, St. Louis, MO, USA) for the identification of all VOCs listed in Table 1 and Table 3 and in case of Germacrene D, Curcumene and $(E, E)$ - $\alpha$-Farnesene, where we did not have standard compounds, we verified the VOC identity by calculating Kovats retention indices. Additionally, mass spectra were compared with those in the NIST and Wiley mass spectra libraries. Individual compounds were quantified by comparing the peak areas in the FID traces with that of the internal standard (nonyl acetate) calculated according to the effective carbon number concept described by Scanion and Willis (1985).

\section{Plant harvest and herbivory measurements}

After VOC collection, herbivory of the focal $T$. pratense plants was estimated visually. Thus, percent leaf area loss in each of the three leaflets of a leaf (between 20 and 30 leaves in each plant) was scored and then an average leaf area loss per leaf was calculated for each plant individual. After herbivory had been estimated, focal $T$. pratense were harvested separately from the rest of the community by cutting the plant $3 \mathrm{~cm}$ above the ground. The harvested plants were freeze-dried and the dry weight of each individual was then determined. The other plants in the community as well as control plant communities were also harvested, pooled by species and the dry weight was determined after plants were dried for $48 \mathrm{~h}$ at $70^{\circ} \mathrm{C}$. VOC measurements and biomass harvesting were performed on separate days for the different blocks.

\section{Statistical analysis}

All analyses were carried out using the software package R (https://www.r-project.org/), version 3.4.1. All statistical assumptions such as homogeneity of the variances and normality were checked and the VOC emission data of the focal $T$. pratense plants $\left(\mathrm{ng} \mathrm{g}^{-1} \mathrm{~h}^{-1}\right)$ was log- transformed before statistical testing. The proportions of VOCs emitted were calculated as proportions of total emission and arcsine transformed before statistical analysis. The data was then analyzed using analysis of variance (aov), except for the numbers of compounds emitted from the community, which were analyzed using a generalized linear model (glm) with poisson error distribution, because the count data were not normally distributed.

In our design, plant species richness (1-3 plant species), composition (T, TD, TG, TGD), and the presence of a plant species additional to T. pratense (i.e. D or G) were confounded in our design, e.g. increasing plant species richness was only possible be including an additional plant species. This is because we only had three species in our experiment. Thus, we cannot put all terms (species richness, composition, presence of particular species) into the same model. Nevertheless, it is important to understand which of these different explanatory variables has the largest effect. After consulting statisticians, we decided for the following approach in the statistical analysis: for each dependent variable, we run different statistical models (procedures aov and glm in $\mathrm{R}$, depending on the variable type, see above), one focusing on plant species richness (model 1), one on species composition (model 2) and one on neighbor species identity (model 3), i.e. the species G. pratense and D. glomerata. We run each model separately and compared their results using the AIC, to see which model explained the patterns best, i.e. had the lowest AIC. However, because we know that that the different types of independent variables are confounded, we are careful not to state that one variable (e.g. species richness) is more important than the other (e.g. composition), rather, we neutrally state if a particular variable has a significant effect and how this effect compares to the effect of the others.

Thus, the data was analyzed as follows: the effects of species richness (3 levels), species composition (four levels) and neighbor species identity (presence/absence of D. glomerata and G. pratense) on VOC emissions of focal plants, or the entire community, were tested in separate analyses of variance models with each factor as the main effect, and block as a random effect. Interaction effects between herbivory and species richness and herbivory and species identity were also tested. In our statistical analysis, we followed the procedure of model simplification [7]: the models were simplified until the minimum adequate model was achieved. The initial models were as follows:

\section{Model 1 (species richness):}

y Block + Herbivory + Species richness + Herbivory * species richness 
Model 2 (species composition):

y Block + Herbivory + Species composition + (Species composition "Herbivory)

Model 3 (species identity):

$\mathrm{y} \sim$ Block + Herbivory+ G. pratense $(0,1)+D$. glomerata $(0,1)+($ Herbivory" G. pratense $)+(D$. glomerata " Herbivory)

where $\mathrm{y}$ was either VOC emission of the T. pratense plant or of the entire plant community (either individual compounds or total compounds). Plant biomass and plant community herbivory (in this case without the variable herbivory as a predictor) were also tested with these models. Thus, for every analysis (using aov or $\mathrm{glm}$ ), we always tested the three different models.

The Akaike information criterion (AIC) was used to determine the goodness of fit of the different models and to compare models [7]. Since each variable (y) was analyzed three times to test effects of species richness, composition and species identity, $p$ values were adjusted using the false discovery rate (FDR) method to avoid false positives associated with multiple hypothesis testing.

There were three missing values in the community data and four missing values in the single plant measurements. This was due to low signal to noise ratios in the VOC measurements of these plants. Additionally, one value in the single plant measurements was considered an outlier and thus removed from the statistical analysis.

For ease of reading, results of the statistical analyses are summarized in tables, Note that in the main body of the text, tables are condensed to save space, more detailed versions of the statistical tables are given in the supplement.

\section{Additional files}

Additional file 1: Figure S1. (A) Biomass of the focal plant Trifolium pratense growing in different mixtures and (B) biomass of entire experimental plant communities. The biomass of the focal T. pratense plants was affected by plant species richness, species composition and the identity of the neighbouring plants. T. pratense individuals growing in plant species mixtures had a lower biomass than individuals growing in monocultures. For entire plant communities, species richness, species composition and the identity of the neighbouring plants affected total biomass. Biomass was highest in the most diverse community and communities with $D$. glomerata were found to have higher biomass than other communities. Table S1. Statistical results for (A) biomass of the focal plant Trifolium pratense growing in different mixtures and (B) biomass of entire plant communities. Figure S2. Percent leaf area loss due to Spodoptera littoralis feeding on the focal Trifolium pratense plants growing in different mixtures. The percent leaf area loss due to Spodoptera littoralis caterpillar feeding was on average $18.4 \pm 2.0 \%$. Herbivory tended to increase with species richness, but this was not significant. Plant species composition and neighbor identity did not affect caterpillar herbivory. Table S2. Statistical results for herbivory on
Trifolium pratense growing in different plant species mixtures. Table S3. Statistical results for the effect of herbivory on the emission of individual compounds from the headspace of (A) individual Trifolium pratense and (B) from the headspace of entire communities of different plant species mixtures. (DOCX $152 \mathrm{~kb}$ )

Additional file 2: Table S4. Full statistical results for the VOC emission of individual Trifolium pratense plants growing in different experimental plant communities (extension of Table 2). (DOCX 29 kb)

Additional file 3: Table S5. Full statistical results for the VOC emission of entire experimental plant communities (extension of Table 4). (DOCX $32 \mathrm{~kb}$ )

\section{Abbreviations}

C: Non-infested control plants; DMNT: 4,8-dimethyl-1,3,7-nonatriene; H: Plants infested with Spodoptora littoralis caterpillars; HIPV: Herbivore induced plant volatiles; PET: Polyethylene terephthalate; T: Trifolium pratense monoculture; TD: Two-species mixture containing T. pratense and Dactylis glomerata; TDG: Three species mixture with T. pratense, D. glomerata and G. pratense; TG: Two-species mixture containing T. pratense and Geranium pratense; VOC: Volatile organic compounds

\section{Acknowledgements}

We thank the MPI-CE greenhouse team for help with plant rearing.

\section{Funding}

This research was funded by the International Max Planck Research School in Jena and the Max Planck Society.

\section{Availability of data and materials}

All supporting data are included as additional files. The datasets used and analyzed during the current study are available from the corresponding author on reasonable request.

\section{Authors' contributions}

RNK, SBU and WWW conceived the study and RNK and SBU designed the experiments; RNK performed the experiments, analyzed the data together with MR and drafted the manuscript. JG, SBU and WWW substantially revised the manuscript. All authors read and approved the final manuscript.

\section{Ethics approval and consent to participate}

Not applicable.

\section{Consent for publication}

Not applicable.

\section{Competing interests}

The authors declare that they have no competing interests.

\section{Publisher's Note}

Springer Nature remains neutral with regard to jurisdictional claims in published maps and institutional affiliations.

\section{Author details}

${ }^{1}$ Institute of Ecology, Friedrich-Schiller-University of Jena, Dornburger Str. 159, 07743 Jena, Germany. ${ }^{2}$ Department of Biochemistry, Max Planck Institute for Chemical Ecology, Hans-Knöll Str. 8, 07745 Jena, Germany. ${ }^{3}$ Present Address: Terrestrial Ecology Research Group, Department of Ecology and Ecosystem Management, School of Life Sciences Weihenstephan, Technische Universität München, Hans-Carl-von-Carlowitz-Platz 2, 85354 Freising, Germany. ${ }^{4}$ Present Address: Department of Biological Sciences, Pwani University, P.O Box 195-80108, Kilifi, Kenya.

Received: 8 January 2018 Accepted: 20 November 2018 Published online: 06 February 2019

References

1. Ballhorn DJ, Kautz S, Schadler M. Induced plant defense via volatile production is dependent on rhizobial symbiosis. Oecologia. 2013;172: $833-46$. 
2. Bendara M, Ekesi S, Ndung'u M, Srinivasan R, Torto B. A major host plant volatile, 1-octen-3-ol, contributes to mating in the legume pod borer, Maruca vitrata (Fabricius) (Lepidoptera:Crambidae). Naturwissenschaften. 2015;102:47.

3. Broz AK, Broeckling CD, De-La-Pena C, Lewis MR, Greene E, Callaway RM, Sumner LW, Vivanco JM. Plant neighbor identity influences plant biochemistry and physiology related to defense. BMC Plant Biol. 2010; 10:115.

4. Clavijo McCormick A, Irmisch S, Reinecke A, Boeckler GA, Veit D, Reichelt M, Hansson BS, Gershenzon J, Köllner TG, Unsicker SB. Herbivore-induced volatile emission in black poplar: regulation and role in attracting herbivore enemies. Plant Cell and Environment. 2014a;37:1909-23.

5. Clavijo McCormick A, Unsicker SB, Gershenzon J. The specificity of herbivore-induced plant volatiles in attracting herbivore enemies. Trends Plant Sci. 2012;17:303-10.

6. Clavijo McCormick AC, Gershenzon J, Unsicker SB. Little peaks with big effects: establishing the role of minor plant volatiles in plant-insect interactions. Plant Cell and Environment. 2014b;37:1836-44.

7. Crawley MJ. The R Book: John Wiley \& Sons, Ltd; 2007. https://doi.org/10. 1002/9780470515075.

8. Dassler A, Roscher C, Temperton VM, Schumacher J, Schulze ED. Adaptive survival mechanisms and growth limitations of small-stature herb species across a plant diversity gradient. Plant Biol. 2008;10:573-87.

9. Dicke M. Behavioural and community ecology of plants that cry for help. Plant Cell and Environment. 2009;32:654-65.

10. Dicke M, Baldwin IT. The evolutionary context for herbivore-induced plant volatiles: beyond the 'cry for help'. Trends Plant Sci. 2010;15:167-75.

11. Dicke M, van Poecke RMP, de Boer JG. Inducible indirect defence of plants: from mechanisms to ecological functions. Basic and Appl Ecology. 2003;4:27-42.

12. Ebeling A, Klein A-M, Schumacher J, Weisser WW, Tscharntke T. How does plant richness affect pollinator richness and temporal stability of flower visits? Oikos. 2008;117:1808-15

13. Ebeling A, Hines J, Hertzog LR, Lange M, Meyer ST, Simons NK, Weisser WW Plant diversity effects on arthropods and arthropod-dependent ecosystem functions in a biodiversity experiment. Basic and Appl Ecology. 2017; 26(2018)50-63.

14. Eberl F, Hammerbacher A, Gershenzon J, Unsicker SB. Leaf rust infection reduces herbivore-induced volatile emission in black poplar and attracts a generalist herbivore. The New Phytologist. 2017. https://doi.org/10.1111/ nph.14565.

15. Engelberth J, Alborn HT, Schmelz EA, Tumlinson JH. Airborne signals prime plants against insect herbivore attack. Proc Natl Acad Sci U S A. 2004;101: 1781-5.

16. Erb M, Veyrat N, Robert CA, Xu H, Frey M, Ton J, Turlings TC. Indole is an essential herbivore-induced volatile priming signal in maize. Nat Commun. 2015;6:6273.

17. Fontana A, Reichelt M, Hempel S, Gershenzon J, Unsicker SB. The effects of arbuscular mycorrhizal fungi on direct and indirect defense metabolites of Plantago lanceolata L. J Chem Ecol. 2009;35:833-43.

18. Frost CJ, Appel M, Carlson JE, De Moraes CM, Mescher MC, Schultz JC. Within-plant signalling via volatiles overcomes vascular constraints on systemic signalling and primes responses against herbivores. Ecol Lett. 2007; 10:490-8.

19. Gols R, Bukovinszky T, Hemerik L, Harvey JA, Van Lenteren JC, Vet LEM Reduced foraging efficiency of a parasitoid under habitat complexity: implications for population stability and species coexistence. J Anim Ecol. 2005;74:1059-68.

20. Gouinguene SP, Turlings TCJ. The effects of abiotic factors on induced volatile emissions in corn plants. Plant Physiol. 2002;129:1296-307.

21. Gubsch M, Roscher C, Gleixner G, Habekost M, Lipowsky A, Schmid B, Schulze E-D, Steinbeiss S, Buchmann N. Foliar and soil delta $15 \mathrm{~N}$ values reveal increased nitrogen partitioning among species in diverse grassland communities. Plant Cell and Environment. 2011a;34:895-908.

22. Hare JD. Ecological role of volatiles produced by plants in response to damage by herbivorous insects. Annu Rev Entomol. 2011;56:161-80.

23. Hilker M, McNeil J. Chemical and behavioral ecology in insect parasitoids: how to behave optimally in a complex odorous environment. In: Wajnberg E, Bernstein C, van Alphen J, editors. Behavioral ecology of insect parasitoids: from theoretical approaches to field applications. Malden: Wiley-Blackwell; 2008. p. 92-112
24. Himanen SJ, Blande JD, Klemola T, Pulkkinen J, Heijari J, Holopainen JK. Birch (Betula spp) leaves adsorb and re-release volatiles specific to neighbouring plants - a mechanism for associational herbivore resistance? New Phytol. 2010;186:722-32.

25. Hogh-Jensen H, Schjoerring JK. Interactions between white clover and ryegrass under contrasting nitrogen availability: N2 fixation, N fertilizer recovery, $\mathrm{N}$ transfer and water use efficiency. Plant Soil. 1997;197:187-99.

26. Holopainen JK, Gershenzon J. Multiple stress factors and the emission of plant VOCs. Trends Plant Sci. 2010;15:176-84.

27. Johnson D, Gilbert L. Interplant signalling through hyphal networks. New Phytol. 2015;205:1448-53.

28. Junker RR, Bluethgen N. Floral scents repel facultative flower visitors, but attract obligate ones. Ann Bot. 2010;105:777-82.

29. Karban R, Baldwin IT, Baxter KJ, Laue G, Felton GW. Communication between plants: induced resistance in wild tobacco plants following clipping of neighboring sagebrush. Oecologia. 2000;125:66-71.

30. Karban R, Shiojiri K, Ishizaki S, Wetzel WC, Evans RY. Kin recognition affects plant communication and defence. Proc R Soc B Biol Sci. 2013;280: 20123062

31. Kegge W, Pierik R. Biogenic volatile organic compounds and plant competition. Trends Plant Sci. 2010;15:126-32.

32. Kegge W, Weldegergis BT, Soler R, Vergeer-Van Eijk M, Dicke M, Voesenek LA, Pierik R. Canopy light cues affect emission of constitutive and methyl jasmonate-induced volatile organic compounds in Arabidopsis thaliana. New Phytol. 2013;200:861-74

33. Kempel A, Schmidt AK, Brandl R, Schadler M. Support from the underground: induced plant resistance depends on arbuscular mycorrhizal fungi. Funct Ecol. 2010;24:293-300.

34. Kigathi RN, Unsicker SB, Reichelt M, Kesselmeier J, Gershenzon J, Weisser WW. Emission of volatile organic compounds after herbivory from Trifolium pratense $(\mathrm{L})$ under laboratory and field conditions. J Chem Ecol. 2009;35: 1335-48.

35. Kigathi RN, Weisser WW, Veit D, Gershenzon J, Unsicker SB. Plants suppress their emission of volatiles when growing with conspecifics. J Chem Ecol. 2013;39:537-45

36. Kost C, Heil M. Herbivore-induced plant volatiles induce an indirect defence in neighbouring plants. J Ecol. 2006:94:619-28.

37. Leitner M, Boland W, Mithofer A. Direct and indirect defences induced by piercing-sucking and chewing herbivores in Medicago truncatula. New Phytol. 2005;167:597-606.

38. Leitner M, Kaiser R, Hause B, Boland W, Mithofer A. Does mycorrhization influence herbivore-induced volatile emission in Medicago truncatula? Mycorrhiza. 2010;20:89-101.

39. Loranger H, Weisser WW, Ebeling A, Eggers T, De Luca E, Loranger J, Roscher C, Meyer ST. Invertebrate herbivory increases along an experimental gradient of grassland plant diversity. Oecologia. 2014;174:183-93.

40. Loreto F, Pollastri S, Fineschi S, Velikova V. Volatile isoprenoids and their importance for protection against environmental constraints in the Mediterranean area. Environ Exp Bot. 2014;103:99-106.

41. Meiners T. Chemical ecology and evolution of plant-insect interactions: a multitrophic perspective. Current Opinion in Insect Science. 2015;8:22-8.

42. Meiners T. In: Blande JD, Glinwood R, editors. Ecological Role of Odour Diversity In: Deciphering Chemical Language of Plant Communication; 2016. p. 137-51.

43. Mraja A, Unsicker SB, Reichelt M, Gershenzon J, Roscher C. Plant community diversity influences allocation to direct chemical defence in Plantago lanceolata. PLoS One. 2011;6:e28055.

44. Mumm R, Dicke M. Variation in natural plant products and the attraction of bodyguards involved in indirect plant defense. Can J Zool-Revue Canadienne De Zoologie. 2010;88:628-67.

45. Oikawa PY, Lerdau MT. Catabolism of volatile organic compounds influences plant survival. Trends Plant Sci. 2013;18:695-703.

46. Ozawa R, Shimoda T, Kawaguchi M, Arimura G, Horiuchi J, Nishioka T, Takabayashi J. Lotus japonicus infested with herbivorous mites emits volatile compounds that attract predatory mites. J Plant Res. 2000;113:427-33.

47. Pierik R, Ballare CL, Dicke M. Ecology of plant volatiles: taking a plant community perspective. Plant Cell Environ. 2014:37:1845-53.

48. Randlkofer B, Obermaier E, Casas J, Meiners T. Connectivity counts: disentangling effects of vegetation structure elements on the searching movement of a parasitoid. Ecol Entomol. 2010a;35:446-55. 
49. Randlkofer B, Obermaier E, Hilker M, Meiners T. Vegetation complexity: the influence of plant species diversity and plant structures on plant chemical complexity and arthropods. Basic and Appl Ecol. 2010b;11:383-95.

50. Rodriguez A, Alquezar B, Pena L. Fruit aromas in mature fleshy fruits as signals of readiness for predation and seed dispersal. New Phytol. 2013; 197:36-48.

51. Roscher C, Thein S, Weigelt A, Temperton VM, Buchmann N, Schulze E-D. N2 fixation and performance of 12 legume species in a 6-year grassland biodiversity experiment. Plant Soil. 2011b;341:333-48.

52. Schmelz EA, Alborn HT, Engelberth J, Tumlinson JH. Nitrogen deficiency increases volicitin-induced volatile emission, jasmonic acid accumulation, and ethylene sensitivity in maize. Plant Physiology. 2003;133:295-306.

53. Schroeder R, Hilker $\mathrm{M}$. The relevance of background odor in resource location by insects: a behavioral approach. Bioscience. 2008;58:308-16.

54. Snoeren TAL, De Jong PW, Dicke M. Ecogenomic approach to the role of herbivore-induced plant volatiles in community ecology. J Ecol. 2007; 95:17-26.

55. Tabata J, De Moraes CM, Mescher MC. Olfactory cues from plants infected by powdery mildew guide foraging by a mycophagous ladybird beetle. PLoS One. 2011;6(8):e23799.

56. Thein S, Roscher C, Schulze E-D. Effects of trait plasticity on aboveground biomass production depend on species identity in experimental grasslands. Basic Appl Ecol. 2008;9:475-84

57. Unsicker SB, Franzke A, Specht J, Kohler G, Linz J, Renker C, Stein C, Weisser WW. Plant species richness in montane grasslands affects the fitness of a generalist grasshopper species. Ecology. 2010;91:1083-91.

58. Unsicker SB, Kunert G, Gershenzon J. Protective perfumes: the role of vegetative volatiles in plant defense against herbivores. Curr Opin Plant Biol. 2009;12:479-85

59. Waschke N, Hardge K, Hancock C, Hilker M, Obermaier E, Meiners T. Habitats as complex odour environments: how does plant diversity affect herbivore and parasitoid orientation? PLoS One. 2014;9:e85152.

60. Weisser WW, Roscher C, Meyer ST, Ebeling A, Luo G, Allan E, Beßler H, Barnard RL, Buchmann N, Buscot F, Engels C, Fischer C, Fischer M, Gessler A, Gleixner G, Halle S, Hildebrandt A, Hillebrand H, de Kroon H, Lange M, Leimer S, Le Roux X, Milcu A, Mommer L, Niklaus PA, Oelmann Y, Proulx R, Roy J, Scherber C, Scherer-Lorenzen M, Scheu S, Tscharntke T, Wachendorf M, Wagg C, Weigelt A, Wilcke W, Wirth C, Schulze E-D, Schmid B, Eisenhauer N. Biodiversity effects on ecosystem functioning in a 15-year grassland experiment: patterns, mechanisms, and open questions. Basic Appl Ecol. 2017:23:1-73.

61. Wood WF, Archer CL, Largent DL. 1-Octen-3-ol, a banana slug antifeedant from mushrooms. Biochem Syst Ecol. 2001;29:531-3.

Ready to submit your research? Choose BMC and benefit from:

- fast, convenient online submission

- thorough peer review by experienced researchers in your field

- rapid publication on acceptance

- support for research data, including large and complex data types

- gold Open Access which fosters wider collaboration and increased citations

- maximum visibility for your research: over $100 \mathrm{M}$ website views per year

At BMC, research is always in progress.

Learn more biomedcentral.com/submissions 